\title{
Maximum Power Point Box (MPPB) Design to Advance BIPV Installations on Residential Properties
}

\author{
Chadi Nohra ${ }^{1}$, Mohamad Nassereddine ${ }^{2}$ \\ ${ }^{1}$ Department of Electrical and Computer Engineering, Beirut Arab University, Tripoli, Lebanon \\ ${ }^{2}$ Department of Electrical \& Computer Engineering, University of Wollongong in Dubai, Dubai, United Arab Emirate
}

\begin{tabular}{l}
\hline \hline Article Info \\
\hline Article history: \\
Received Apr 5, 2020 \\
Revised Mar 19, 2021 \\
Accepted Mar 22, 2021 \\
\hline
\end{tabular}

\section{Keywords:}

BIPV

Maximum Power Point

Photovoltaic

Power Management

Sustainable House

\begin{abstract}
Photovoltaic installations on residential properties gained high momentums during the past decade. Building integrated photovoltaic materials are well developed and has the potential to advance the photovoltaic systems installations on residential and commercial buildings. One of the main limitations on residential system is the utility allowable AC power generation. The installation of BIPV on houses offer numerous orientation and tilts of the PV system which ensure sun energy is harvested for wider timeframe. The different orientations and tilts reflect changes in the generate output power. The available residential inverters have one of two MPPTs which limit the orientation and tilts of the system to a maximum of two options per inverter. Adding more inverters will add cost burden on the system, exceed the utility maximum allowable AC power generation, and additional inverters will not work at rated power throughout the day. The works in this paper include the detail design of a maximum power point box (MPPB) that harvest the sun energy for different orientations and tilts, manage and regulate the DC Bus Bar voltage level as well as generated DC power prior the inverter input terminal. The process is governed by an input from the inverter using an industrial communication protocol such as MODBUS. The aim of the box is to reduce the number of inverters required for maximum power generation while maintaining the maximum AC limits set the by utilities. The paper includes the details design with the proposed circuit along its optimum logics. Case study is also included
\end{abstract}

Copyright $(2021$ Institute of Advanced Engineering and Science. All rights reserved.

\footnotetext{
Corresponding Author:

Mohamad Nassereddine,

Department of Electrical and Computer Engineering,

University of Wollongong in Dubai,

Media City, Dubai, United Arab Emirate.

Email: mnassereddine@ieee.org
}

\section{INTRODUCTION}

The United Nation (UN) along numerous governments acknowledged the risk of climate change and set regulations and policies to address these issues [1-3]. Photovoltaic (PV) systems are one of the main renewable energy systems that UN and Government promote to mitigate the climate change impact on the planet. PV technology converts solar energy into electric power without any gas emissions [4-6]. Numerous governments introduce an incentive benefits for owners (residential and commercial) to install PV systems on their properties [7-8]. These incentives and other factors increased the installation of small microgrid system especially on residential properties [9]. This dramatical increase of PV system installation has the potential to impact on the current network. These impacts could be in the form of voltage variation, unbalance harmonics and stress on distribution transformer [9-12]. To reduce the impact on the utility grid, policies are set in place to limit the installed renewable energy system size for single and three phase projects. The limitation of the maximum AC power generation by the micro-grid control or reduces the impact that the installed PV system could indorse on the electrical network. However, this limitation along with the sun path throughout the day 
and year, reduce the house generation capacity. The sun path changes throughout the day which reflect on the PV output $[13,14]$. To maximize the sun energy at the PV system, the designer should follow the sun path using a mechanical tracking devise [15]. For residential properties, the PV system is installed on the roof which makes it very costly to install a mechanical tracking devise. Without the tracking devise, the peak output of the installed system occurs during short period of the day. The designer is forced to size the inverter to comply with the peak generation period which only exist during short time of the day. Furthermore, the inverter is equipped with maximum power point tracker (MPPT) to extract the maximum possible power from the PV panels [16-18]. The PV panels that is installed to one MPPT should have the same orientation and tilts. Therefore, for an inverter to capture more orientations, additional number of MPPT should be part of the proposed inverter. Unfortunately, the currently available inverters for residential properties for single phase systems has one or two MPPTs. The limited number of MPPTs limit the number of orientations and tilts to a maximum of two for small scale residential properties.

The work in this paper focuses on the detailed design of a maximum power point box (MPPB) to allow for numerous orientations and tilts connection of PV arrays at residential properties systems. The paper shows how the MPPB allows house owner to track the sun using additional panels to maximize the system outputs. The proposed system can make use of the building integrated PV materials to reduce the cost of the installed system. Case study is also included

\section{THEORETICAL STUDY}

The PV system converts the sun light into electrical direct current. The circuit in Figure 1 represents the PV system as a current source [19-27]. The solar cell is presented using current source, diode and resistors. The generated current magnitude depends on the sun radiations and temperature. Figure 2 represents the shape of the output of a solar cell.

Rs

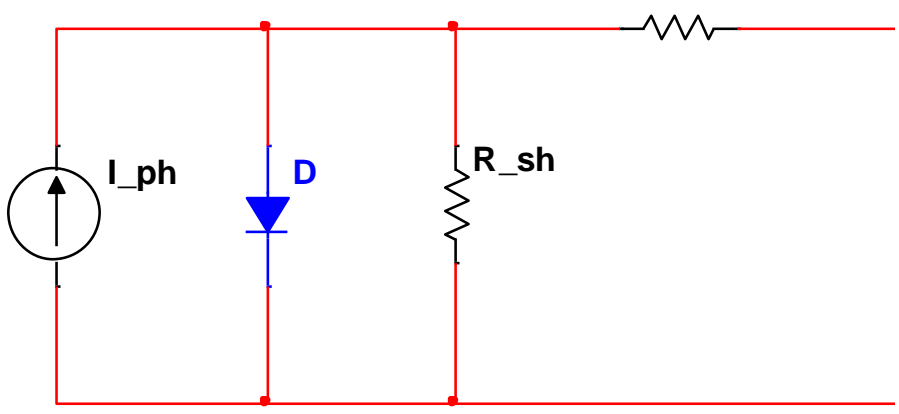

Figure 1. Circuit representation for solar cell

It is clearly shown in Figure 2 the changes in PV output with the change in solar radiations. The solar radiation at the PV panels depends on the seasons, day time, tilt and orientation of the panels. It is possible for the sun radiation to be at one Sun however the sun at the panels is below $0.5 \mathrm{Sun}$. it is worth nothing that one Sun is equate to $1000 \mathrm{~W} / \mathrm{m}^{2}$ of radiation. Based on this information, the orientation and tilt play an important role in maximizing the energy output of the installed PV system.

From Figure 2, the output current of the PV panel under fixed radiation stays constant until the voltage reaches a certain value then dive toward zero. Also checking the power output behavior, the power increases until reaches maximum value at a nominal voltage before it dives toward the zero. This phenomenon urged researchers to introduce maximum power point tracker (MPPT) to regulate the voltage that reflect maximum output power [27-29].

The output power of PV panel is a function of the following variables:

- Characteristics of the PV panels

- Sun radiations in $\mathrm{Wm} 2$

- $\quad$ Tilt angle of the panels

- Sun radiation incident angel to the surface

As the sun moves throughout the day, the sun radiation on the fixed panel orientation changes which reflect a change in power outputs.

$$
P_{p v}=\text { function of }\left\{\begin{array}{c}
\text { Sun_Radiation } \\
\text { Panel_Tilt_Angle } \\
\text { Radiation-Incident_Angle }
\end{array}\right\}
$$



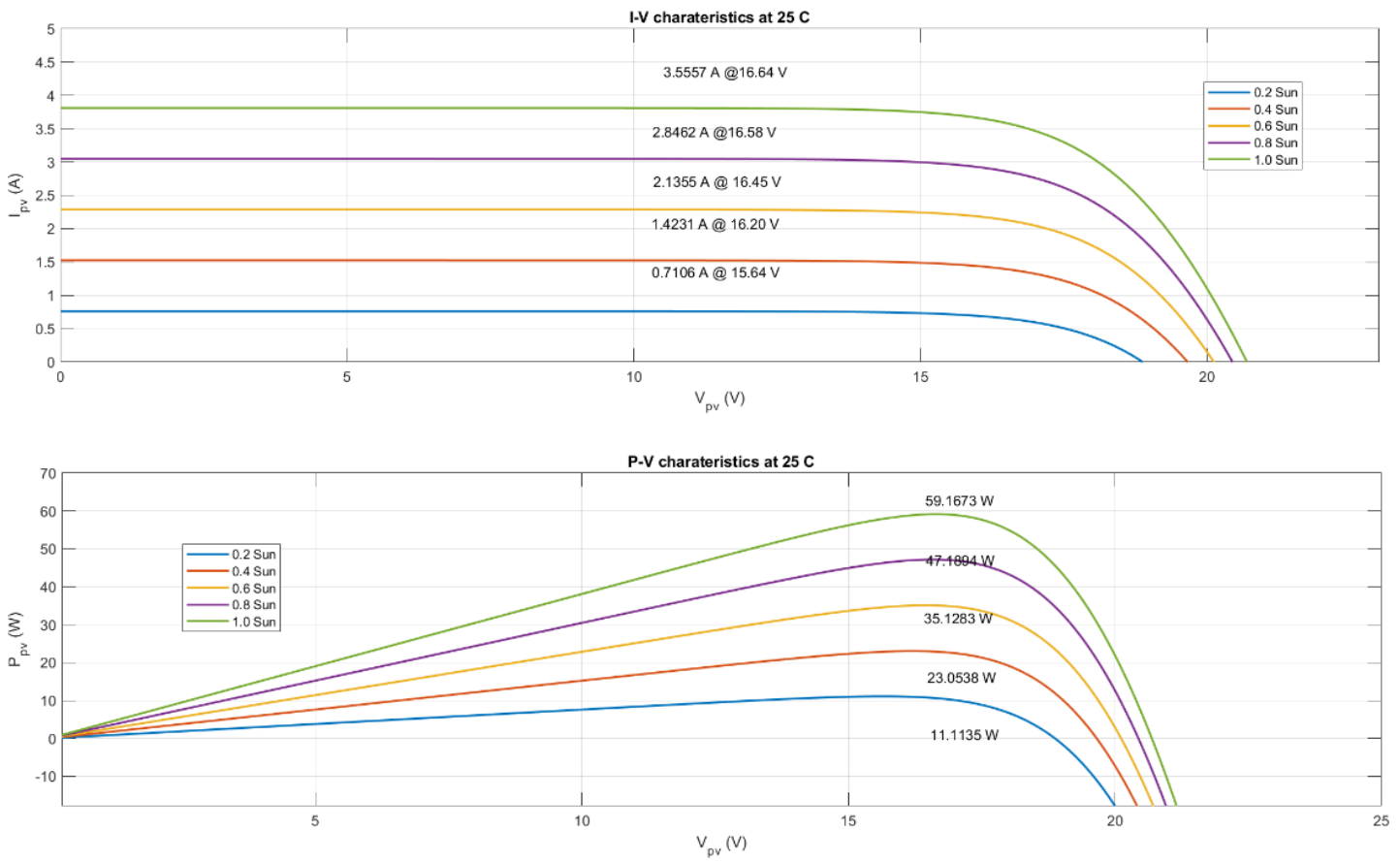

Figure 2. PV output in relation to sun radiation

Figure 3 shows the sun radiation angle to the panels under different tilt angle. It is clearly shown the change in $\mathrm{G}_{\mathrm{i}}$ at the panel $\left(\mathrm{G}_{\mathrm{i}}\right.$ is the amount of radiation that reaches the panels at 90 degrees). In Figure 3, $\mathrm{G}$ is the global radiation that reaches the panels and $\mathrm{G}_{\mathrm{i}}$ is calculated using the $\mathrm{G}$ value, incident angle of sun $\mathrm{G}$ and the tilt angle. The change in current generated from the PV panels is computed using equation 1 [16-18]. Equation 1 shows that the PV current is a function of the sun radiation at 90 degrees on the panel.

$$
I_{p h}=\text { function of } \frac{G_{i}}{G_{n}}
$$

Where

$\mathrm{G}_{\mathrm{i}}$ is the sun radiation at 90 degrees to the panel

$\mathrm{G}$ is the standard sun radiation under test condition of the panels. It is usually $1000 \mathrm{w} / \mathrm{m}^{2}$
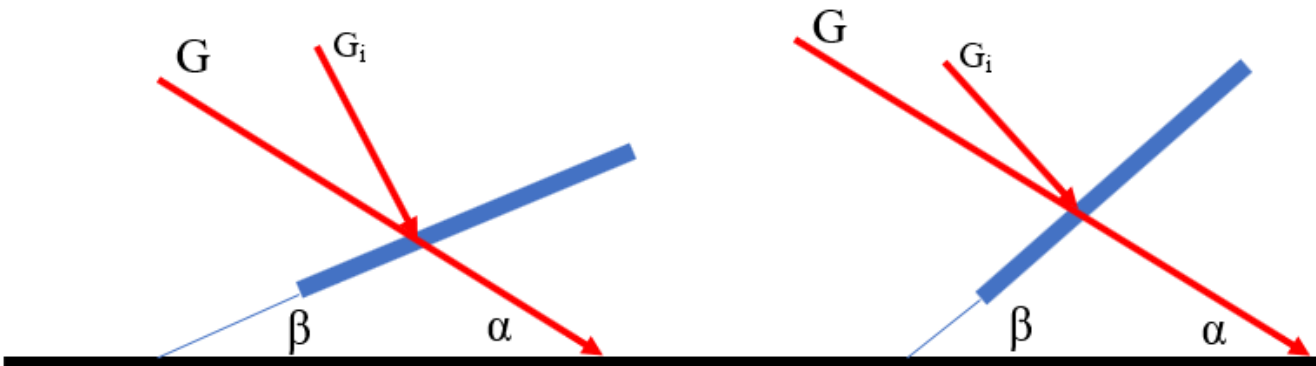

Figure 3. direct radiation on the panels for different tilt angle and sun angle to ground

\subsection{Building Integrated PV (BIPV) System}

The advancement in PV cells technology allows the integration of PV with building materials. These integrationsallow for installation of PV cells under numerous orientations and tilts. Figure 4 shows a possible installation of PV system under the BIPV concept. The system in the figure is formed by vertical BIPV walls facing east and west, one system facing east with tilt of $\beta$, one system facing west with $\beta$ tilt and one system horizontal. The figure shows that at one moment, the sun radiation $\mathrm{G}$ intercept the system under different angle which reflect different $G_{i}$ on each system. It is also worth noting that the West orientated PV system has no direct sun interface which mean no direct $G_{i}$ directed to the installed West BIPV system. Based on this information, during east radiation, the power of the west oriented system is very low in comparison to the east system. The total output power of the house is computed using equation 2 :

$$
P_{h}=\sum_{i=1}^{n} P_{i}
$$


Where

$P_{h}$ is the house total output power of the installed BIPV systems

$n$ is the total number of system with different orientation or tilt. For example, in Fig 4, $\mathrm{n}$ is 5 $P_{i}$ is the individual BIPV system power outputs

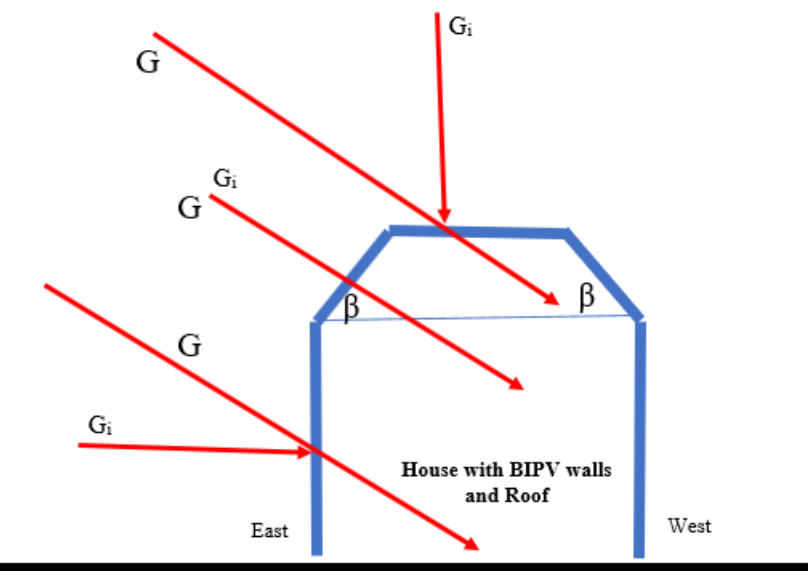

Figure 4. BIPV solar house with different orientations and tilts

\subsection{Solar Irradiance and angles}

The different orientation and tilt of the PV system on the house changes the sun position in relation to the panels. This section contains the information regarding the sun positions in respect of the panel orientation and tilt. The sun position with respect to an observer on earth can be fully described by means of two astronomical angles, the solar altitude $(\alpha)$ and the solar azimuth (z). [30] The solar declination and hour angle need to be defined. These are required in all other solar angle formulations:

1. Declination angle, $\delta$ : The angle between the Sun's direction and the equatorial plane. $\delta$ varies smoothly from $+23.45^{\circ}$ at midsummer in the northern hemisphere, to $-23.45^{\circ}$ at northern midwinter. Declination angle can be determined by [30] $\delta=23.45^{\circ} \sin 360365 n+284$ (1) where $n$ is the day in the year ( $n=1$ on 1 January).

2. Hour angle, $\mathrm{h}$ : is the angle through which the Earth has rotated since solar noon. Since the Earth rotates at $360 \% 24$ hour $=15 \% \mathrm{~h}$. The hour angle is positive in the evening and negative in the morning, the hour angle is given by equation 3 [30]:

$h=$ localtime $-1215^{\circ}$

3. Solar altitude angle, $\alpha$ : The angle between the solar beam and the horizontal.

4. Solar zenith angle, $\phi$ : The angle between the solar beam and the normal on the horizon as shown in Figure 5

5. Solar altitude and solar zenith angles are complementing each other $\left(\alpha+\phi=90^{\circ}\right)$ and calculated by equation 4 [3].

6. Solar azimuth angle, $\mathrm{z}$ : the angle between the solar beam and the longitude meridian. In northern hemisphere, $\mathrm{z}$ equals $0^{\circ}$ for a surface facing due south, $180^{\circ}$ due north, $0^{\circ}$ to $180^{\circ}$ for a surface facing westwards and, $0^{\circ}$ to $-180^{\circ}$ eastward. Equation 5 for is used to compute the solar azimuth angle

$\sin \alpha=\cos \phi=\sin L \sin \delta+\cos L \cos \delta \cos h$

$\sin z=\cos \delta \sinh / \cos \alpha$

where

$L$ is the local latitude, values north of the equator are positive and those souths are negative, $-90<\mathrm{L}$ $<90$.

Determining the sun location and its angle to the ground or to the panels, allow the designer to determine the radiation directed to the panels at 90 degrees. Analyzing Figure 5, the angles can be found to be as follows: 
1. Tilt angle, $\beta$ : is the angle between the plane surface and the horizontal (with $0<\beta<90$ for a surface facing towards the equator; $90<\beta<-90$ for a surface facing away from the equator).

2. Surface azimuth angle, Zs: is the angle between the normal to the surface and the local longitude meridian. Sign convention is as for z. For a horizontal surface, Zs is $0^{\circ}$ always. Zenith angle, angle of incidence, Tilt angle, solar azimuth angle and Surface azimuth angle for a tilted surface [31].

3. Angle of incidence, $\theta$ : the angle between solar beam and surface normal.

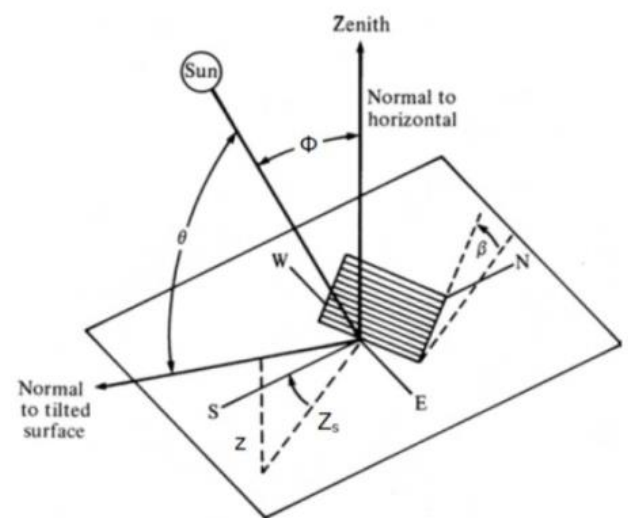

Figure 5. Sun location and its incident on ground and solar panel [30]

\section{MPPB DESIGN}

Many countries set the limit of the grid connected PV system that can be installed at residential properties. The PV output varies between daily hours and seasons. To ensure maximum power is always achieved, additional panel can be installed. The installation of additional panels without a rigid control system will push the system to exceed the allowable generation limits at certain time of the day. The aim of this paper is to design the MPPB system to harvest the required DC energy, when additional panels are installed, without exceeding the inverter requirements or the utility maximum allowed AC power. Also, this approach advances the BIPV implementations worldwide. The role of the MPPB is to collect the maximum power from each set of PV panels using multi MPPT system, acting as intermittent current sources, connected in parallel. Figure 6 shows the setup of the DC control methodology. The system compares the maximum current to a reference current, if the value exceeds the reference value, the system will initiate the PI controller to limit the power, otherwise the system will initiate the MPPT concept to harvest the maximum power of the system.

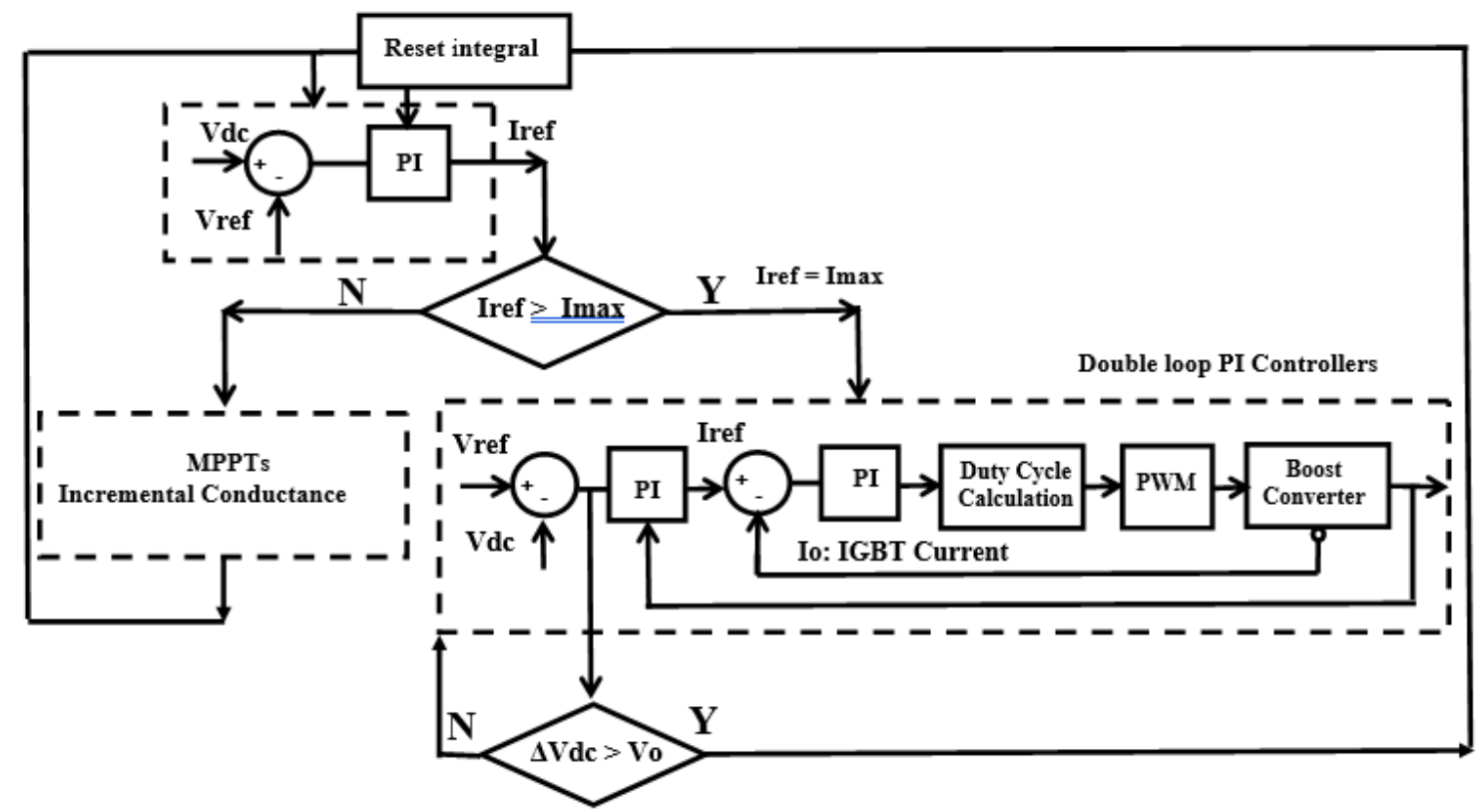

Figure 6. DC power control inside the proposed MPPB 
Figure 7 shows the simulation output of the power controlled using the proposed algorithm, it is clearly shown the power control capability of the MPPB. This ensure the power at the inverter doesn't exceed the desirable limits. This process allows the inverter with the MPPB circuit to install additional PV panels at different orientations. Also Figure 7 shows that adding BIPV has the potential to stabilize the power output for longer day period which advance the system reliability. Figure 8 shows the DC voltage at the common bus bar as well as the $\mathrm{Vdc}$ ref $500 \mathrm{~V}$, the drop in the voltage can be noticed at time 3:00 pm where the irradiance becomes insufficient to generate $15 \mathrm{KW}$ so the MPPt are back on and Iref becomes variable according to the available irradiance.

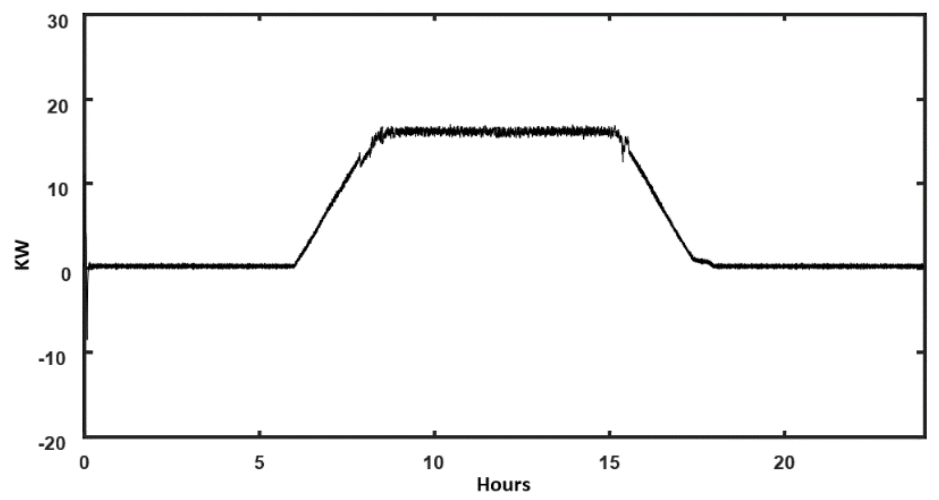

Figure 7. simulation output of the proposed inverter

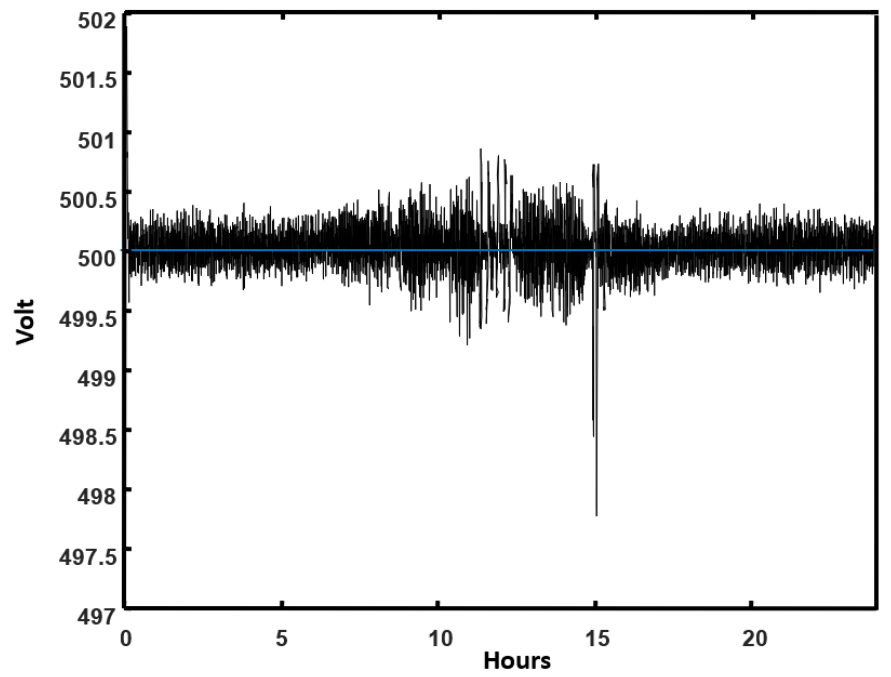

Figure 8. Vdc versus Vdc-ref based on the proposed MPPB

\section{CASE STUDY}

The case study is based on an existing $15 \mathrm{~kW}$ inverter installed with the following data:

- $15 \mathrm{~kW}$ inverter with maximum DC power of $15.25 \mathrm{~kW}$

- Inverter desirable voltage is $500 \mathrm{Vdc}$

- South oriented with tilt angle $23^{\circ}$ at Dubai

The building owner decided to install two additional glass facial walls facing east, west. The size of each wall is $150 \mathrm{~m}^{2}$. The owner decided to use solar panels for the glass walls. Without the MPPB system as proposed in this paper, an additional inverter is required to be installed. The new inverter not only cost money and additional installation on the AC side, it could lead to the change of the existing one (the new inverter must be able to communicate with the existing inverter for synchronization requirements, Also, both inverters maximum AC capacity could exceed the utility allowable limits, so this won't be an acceptable option for the project.

The solution is to control the power generation at the DC level, which is acceptable by utilities and governments. That is why the presence of the MPPB offers a great advantage over system without MPPB. Deploying the paper novel MPPB concept allows for the installation of both walls to be made of BIPV materials 
and for the owner to generate extra power without the need to upgrade or change the AC system. The design ensures each wall has 75 panels of $305 \mathrm{~W}$ connected to the MPPB along with the existing panels. Figure 9 shows the irradiance of each orientation, as well as the total irradiance, during the first of January 2018 at Dubai.

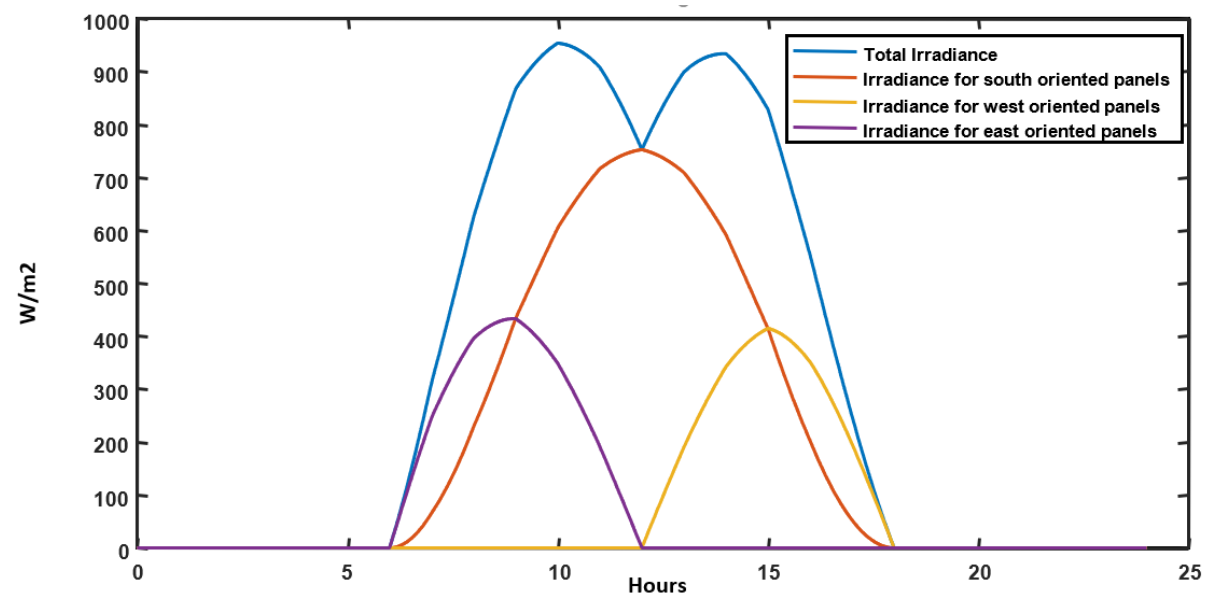

Figure 9. Sun radiation for the first of Jan 2018

Figure 10 shows the connection diagram between the MPPB, Inverter, and Grid. It is worth noting that a data cable required to link between the MPPB and the inverter. The role of the data link is to provide the actual AC power at the output of the inverter which set the reference current at the DC side of the inverter.

The case study simulation outputs are captured in Figure 11. The collected data shows the complete system without capping, which is represented by the extended modeling. It also highlights the capping capability of the system which is presented by the extended system with limitation. The simulation shows the system capability to control the power to the nominal value which allow for the additional panels to be installed at the existing inverter terminal. Table 1 reflects the power generation for the existing systems, the system with additional panels with and without limitations. It is worth noting that this work was verified using system advisory module engineering software.

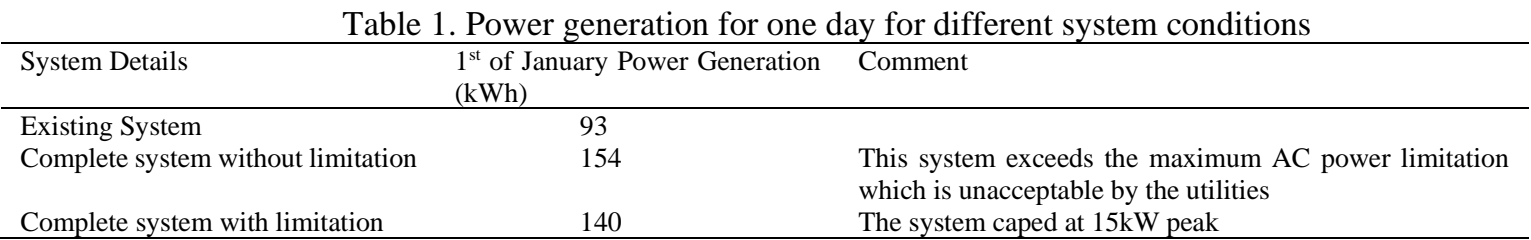

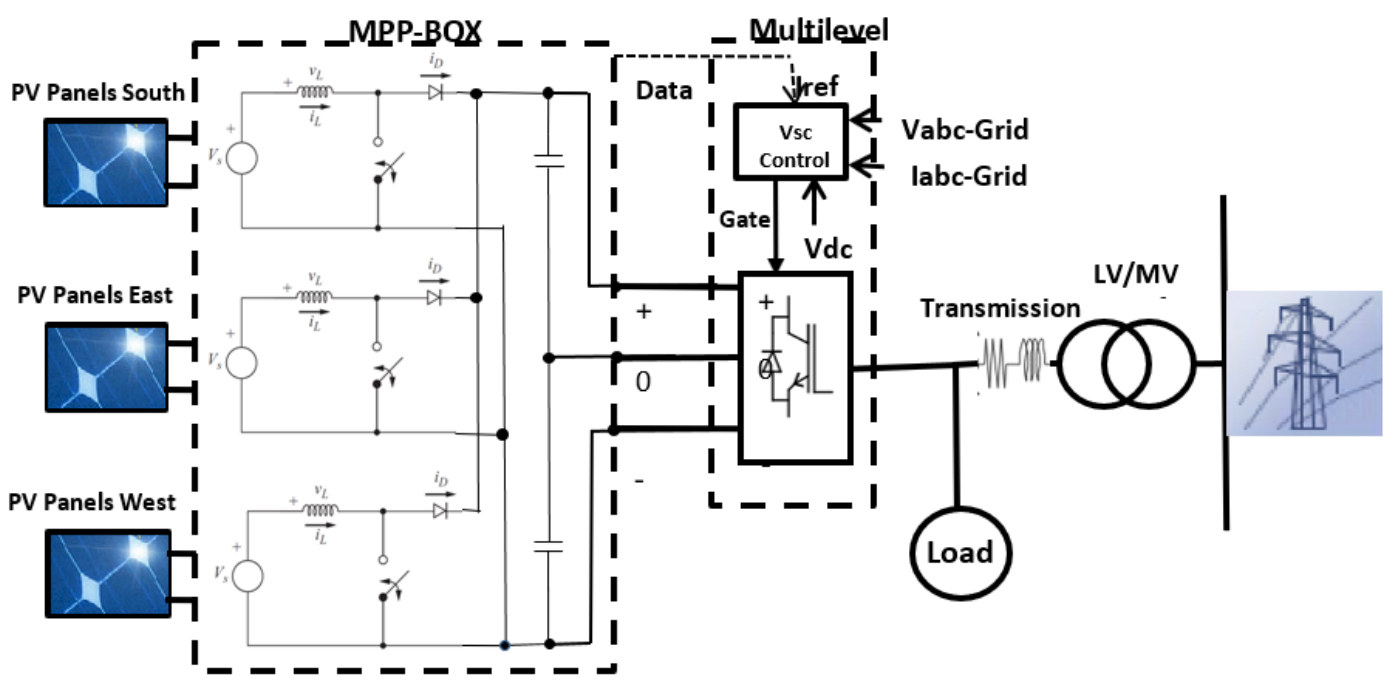

Figure 10. Connection diagram between the panels, MPPB, Inverter and Grid 


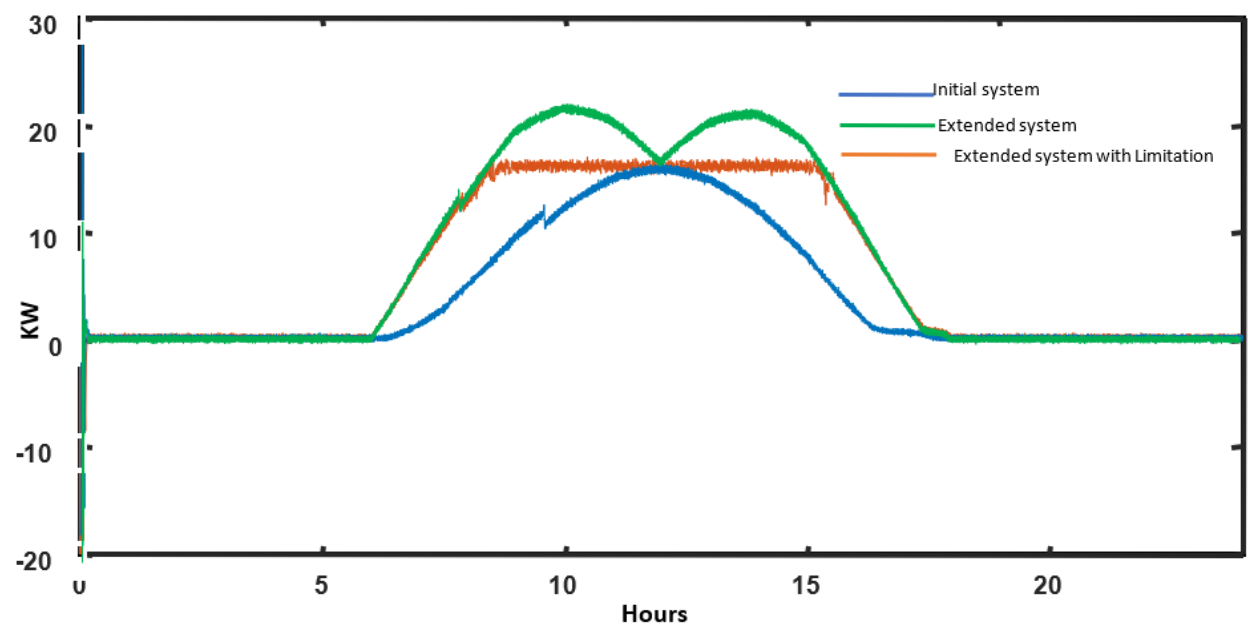

Figure 11. System output data collection under different conditions

\section{CONCLUSION}

The paper addresses an important and growing topic in power generation and renewable energy. The work highlights the importance of controlling the power at the inverter terminal using the proposed MPPB to advance the BIPV implementations. The MPPB box allow house owner to generate additional electrical energy without exceeding the inverter or the utility AC power limits. Without the proposed MPPB, the owner cannot increase the house generation without additional investments in inverter systems if permitted by the utility. Therefore, the proposed MPPB offer an easy solution to owners to increase their generation capacity and to advance BIPV implementations without the requirements of additional alteration to the AC networks. The case study shows the additional benefits that owner can gain from the MPPB. Table 1 shows the advancements in power generation when using BIPV with the proposed MPPB.

\section{REFERENCES}

[1] Bodansky D. "The United Nations framwork convention on climate change: A commentary" Yale Journal of International Law. Issue 2. Vol. 18. PP. 451-558. 1993

[2] Knox J. H. "Linking Human Rights and Climate Change at the United Nation" Harvard Environment Law Review" Vol. 33. PP. 478-498. 2009

[3] Breidenich C., Magraw D., Rowley A. and Rubin J. W. "The kyoto protocol to the united nations framework concention on climate change" The American University Journal of International Law. Vol. 92 Issu 2. PP. 315-331. 1998

[4] Shah A., Torres P., Tscharner R., Wyresch N. and Keppner H. "Photovoltiac technology: the case for thin-film solar cells". Science. Vol. 285. Issue 5428. PP. 692-698. 1999

[5] Mazer JA. "Solar cells. An introduction to crystalline photovoltaic technology" Nehterlands: N. P., 1996. Web.

[6] Rehman S., Shash A., Omar S. and Al-Amoudi B. "Photovoltaic tehcnology of electricyt generation for desert camping" International Journal of Global Energy Issues. Vol. 26 Issue 3/4 PP. 322-340. 2006

[7] Appen J., Braslavsky J., Ward J. and Braun M. "Sizing and grid impact of PV battery systems- acomparative analysis for Australian and Germany" International Symposium on Smart Electric Distribution Systems and Technologies (EDST). Vienna. Sept. 2015

[8] Watt M. and Passey R. "PV in Ausralia 2010" Australian National Photovoltaic Status Report 2010. June 2011

[9] Karimi M., Mokhlis H., Naidu K., Uddin S. and Bakar A.H.A. "Photovoltaic penertration issues and impacts in distribution network- A review" Renewable and Sustainable Energy Reviews. Vol 53. PP. 594-605. 2016

[10] Butler-Purry K.L. and Marotti M. "Impact of distributed generators on protective devices in radial distribution systems". International Transmission and Distribution Conference and Exhibition, 2005/2006 IEEE PES, 2006, pp. $87-88$.

[11] Wu Y-K, Chen C-S, Huang Y-S, Lee C-Y. "Advanced analysis of clustered photovoltaic system's performance based on the battery-integrated voltage control algorithm". International journal of Emerging Electric Power System. Vol. 10. Issue 4. 2009

[12] Albarracín R. and Amarís D.H., "Power quality in distribution power networks with photovoltaic energy sources" International Conference on Enviornment and Electrical Engineering. 2009.

[13] K. Mitchell "Optimisation of the applications of sustainable energy systems" Ph.D. dissertation, School of Engineering and Industrial Design. Univ. Western Sydney 2005.

[14] K. Mitchell, M. Nagrial and J. Rizk "Simulation and optimization of renewable energy systems". Electrical Power and Energy Systems. Vol. 27. PP. 177-177, 2005 
[15] Eke R. and Senturk A. "Performance comparision of a double axis sun tracking versus fixed PV system". Solar Energy. Vol. 86. PP. 2665-2672. 2012

[16] Mohammedi A., Mexxai N., Rekioua D. and Tekioua T. "Impact of shadow on the performances of a domestic photovoltaic pumpin system incorporating an MPPT control: A case study in Bejaia, North Algeria". Energy Conversion and Management. Vol 84. PP20-29. 2014

[17] Walker G. "Evaluating MPPT converter topologies using matlab PV model". Journal of Electrical and Electronics Engineering. Vol 21. Issue 1. PP. 59-55. 2001

[18] Tariq A., Asim M. and Tariq M. "Simulink based modeling simulation and performance evaluation of an MPPT for maximum power generation on resistive load" 2nd International Conference on Environmental Science and Technology. Singapore 2011

[19] Ishaque K., Salam Z., Taheri H. and Syafaruddin "Modeling and simulation of photovoltaic (PV) system during partial shading based on a two-diode model" Simulatiuon Modelling Practice and Theory. Vol 19. PP. 1613-1626. 2011

[20] Chao K.H., Ho S.H. and Wang M.H. "Modeling and fault diagnosis of a photovoltaic system" Electric Power System Research. Vol. 78. PP. 97-105. 2008

[21] Nedumgatt J., Jayakrishnan K., Umashankar S., Vihayakumar D. and Kothari D. "Pertub and observe MPPT algorithm for solar PV systems-modeling and simulation” 2011 Annyal IEEE India Conferenec, Hyderabad, PP. 1-6. 2011

[22] Chiang S.J., Shieh H. J. and Chen M.C. "Modeling and control of PV charger system with SEPIC Converter" IEEE Transaction on Industrial Electronics. Vol. 56 No. 11 PP. 4344-4353. 2009

[23] Safari A. and Mekhilef S. "Simulation and Hardware implementation of incremental conductance MPPT with direct control method using buk converter, ${ }^{\text {eee }}$ IEEE Trans.Ind. Electron., vol . 58, no. 4, Apr. 2011, 1154-1161.

[24] Dhananjay C. and Anmol R.S., "DC-DC Buck Converter for MPPT of PV System", International Journal Of Emerging Technology and Advanced Engineering (IJETAE)., vol. 4, no.7, july 2014, 813-821.

[25] Rodriguez, J.; Jih-Sheng, L.; Fang, P. "Multilevel inverters: A survey of topologies, controls, and applications” IEEE Trans. Ind. Electron. 2002, 49, 724-738

[26] Rodriguez, J.; Bernet, S.; Wu, B.; Point, J.O.; Kouro, S. “Multilevel voltage-source-converter topologies for Industrial medium-voltage drives". IEEE Trans. Ind. Electron. 2007, 54, 2930-2945

[27] Panagis, P.; Stergiopoulos, F.; Marabeas, P.; Manias, S. "Comparison of state-of-the-art multilevel inverters". In Proceedings of the IEEE Annual Power Electronics Specialist Conference PESC, Rhodes Greece,15-19 June 2008

[28] Juri B. and Yoash L. "A Sparse Minimal-Order Dynamic Model of Power Networks Based on dq0 Signals"January 2018IEEE Transactions on Power Systems 33(1):1059-1067

[29] Akram A. and Al-Khazzar A. "A comprehensive solar angles simulation and calculation using Matlab Article · June 2015; International Journal of Energy and Environment. Vol. 6, Issue 4, 2015 pp.367-376

[30] Duffie J.A. and Beckman W.A. "Solar engineering of thermal processes" John Wiley and Sons Inc., New York, 2013.

[31] Ozdemir A. and Erdem Z. "Double-loop PI controller design of the DC-DC boost converter with a proposed approach for calcualtion of the controlle parameters". Proceedings of the institution of Mechanical Engineering Part I. Novmeber 2017

\section{BIOGRAPHY OF AUTHORS}

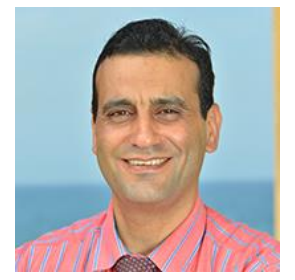

Dr. Chadi Nohra, Associate Professor for Electrical Power and Machines Engineering program at Beirut Arab University, received his PHD degree in the field of Control and Automation from Paul Cezanne University - Aix Marseille III- France. Dr. Nohra Joined Beirut Arab University in Fall 2012. His current research interests include electrical machines control and diagnostics, Diesel modeling \& diagnostics, renewable energy and advance power system for embedded generation and electric vehicles.

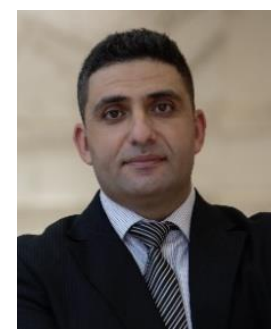

Dr. Mohamad Nassereddine, Assistant professor of electrical engineering, received his Ph.D. degree in the field of High Voltage Power Systems from Western Sydney University. He also received his MEng (Hons) by research in the field of Electric Machine and Renewable Energy from the same university. Dr. Nassereddine has over 15 years industrial experiences and over 10 years academia experience across Australia, Gulf and Middle East regions. Dr Nassereddine is an active presenter for national and international engineering society. $\mathrm{He}$ is also a seinor IEEE memeber. Dr Nassereddine published large number of peer reviewed conferences and journals in the field of power system and renewable energy. 